\title{
Patient mobility in the European Union
}

\author{
Getting healthcare in another European country should be straightforward, but it often \\ creates problems for both patients and healthcare systems
}

In September 2006 the European Commission launched a consultation on health services, focusing mainly on movement of patients across borders. ${ }^{1}$ The longstanding view that health care was the preserve of national governments has been rendered untenable by the European Court of Justice. Its judgments place health services firmly on the European agenda, upholding the right of individuals to obtain care abroad paid for by their home health system in specific circumstances (box). We discuss why patients seek care abroad, examine the medical and legal issues that this raises, and outline some possible responses.

\section{Who seeks care abroad and why?}

The number of people who obtain care in another European country is very low, accounting for at most $1 \%$ of total health expenditure. ${ }^{4}$ Although some people pay for their own care or are reimbursed by insurance policies rather than state systems, this is also likely to be a small fraction of total health expenditure. Nevertheless, the uneven distribution of movement means that in some places, in some circumstances, and for some people the implications can be considerable. We have identified five broad categories of patient mobility: temporary visitors abroad, long term residents retiring to other countries, people living in border areas, people who are referred abroad, and people who seek treatment abroad themselves. All of these groups may experience problems under the current system.

\author{
Helena Legido-Quigley \\ research fellow \\ Martin McKee \\ professor of European public \\ health, London School of \\ Hygiene and Tropical Medicine, \\ London WC1E 7HT

\section{Irene Glinos} \\ research fellow \\ Rita Baeten \\ senior policy analyst \\ Observatoire Sociale Européen, \\ Brussels, Belgium \\ Correspondence to: H Legido- \\ Quigley \\ Helena.legido-quigley@lshtm. \\ ac.uk
}

\section{Box 1 | European legal basis for patient mobility}

The legal basis for patient mobility in Europe was established in 1971 through regulation 1408/712:

- The E111 scheme enabled people temporarily abroad to get treatment if they became ill, with care being paid for by their home funder

- People were also able to obtain care in another country with prior authorisation-for example, someone who had migrated but wanted to return home for treatment of a serious illness or someone who wanted to obtain care unavailable at home. Authorisation could not be refused if the care otherwise available was subject to "undue delay"

In 1998 two rulings by the European Court of Justice (the cases of Kohll ${ }^{3}$ and Decker) relating to spectacles and orthodontic treatment, established that individuals could obtain certain goods and medical service provided outside hospital and be reimbursed by their health funder without getting prior authorisation

A series of cases has since expanded the range of care that can be obtained without authorisation and clarified the principles-for example:

- Patients are entitled to treatment for exacerbations of pre-existing illnesses that occur while abroad

- Decisions to authorise treatment abroad must adhere to "international medical opinion" rather than national policies

- Determination of "undue delay" must take account of the individual circumstances regardless of a standard waiting time guarantee, such as the English patient's charter

\section{Temporary visitors abroad}

Many people now frequently travel abroad. If they fall ill in another European Union country they are entitled to care in local facilities and to be reimbursed by their healthcare funder on presentation of a European Health Insurance Card (which replaced the E111 form). Yet this often does not happen. Official data on claims are barely credible, given the scale of tourist movement. Many claims are never processed and, even when they are, the money obtained centrally is not forwarded to the hospital concerned. ${ }^{5}$ This diminishes the incentive to complete the relevant paperwork, so tourists may not be asked for evidence of entitlement to treatment. In some places, providers may insist on up-front payment that patients have to reclaim from their insurance policy.

Another problem is finding a provider to accept the insurance card. Many tourist resorts have established networks of guides and taxi drivers who channel tourists towards private providers. ${ }^{5} \mathrm{~A}$ survey among returning German tourists who had experienced illness found that only 40\% in Austria and 18\% in Spain had succeeded in using their E111 forms. ${ }^{6}$ We need to ensure that travellers are better informed about their entitlements and to act against those who provide misleading information that channels them to private providers.

\section{People retiring to other countries}

Although there is a long tradition of people retiring to other countries within Europe, most of the movement has been people returning to the country of their birth. This is changing as many people from northern Europe retire to southern Europe. When they do so, money is transferred from the country they came from to the one they are retiring to. These sums are substantial, but there can be a lack of transparency in determining the amounts.

Some of these immigrants may wish to return home to be near families if they need complex care. This is not straightforward, however, as they will have transferred their healthcare entitlement to their new country of residence and will require authorisation. The problems are especially acute for people who divide their time between two countries because the bureaucracy involved in transferring their entitlements back and forth can be extremely daunting, with additional problems if they have chronic disorders requiring continuity of care.

Traditionally, social care for elderly people in southern Europe has been provided by families, but new residents will usually have left their family networks behind. This gap is being filled, partially, by northern 
European organisations such as the UK's Age Concern, which is providing support for older people who have moved to Spain. ${ }^{7}$

\section{People in border regions}

Europe's borders often traverse sparsely populated areas, dividing communities that share common languages and cultures and, in some cases, towns and villages. Facilities are usually duplicated on either side of the border, but increasingly people living in border areas can access care in each others' countries. The Euregio Meuse-Rhine region pioneered collaboration among organisations in the Netherlands, Germany, and Belgium. In another project, French and Catalan authorities are jointly building a hospital in a remote area near Andorra. ${ }^{8}$ Payment for care in shared facilities has often used systems based on existing European rules and procedures, but there are increasing examples of cross border contracts between statutory purchasers and providers, such as those between Dutch health insurers and Belgian hospitals. ${ }^{9}$

Cross border collaboration presents many practical problems, ranging from the incompatibility of sirens on emergency vehicles to different payment mechanisms. ${ }^{10}$ Another is the nationality of children born in a shared obstetric unit. The authorities in France and Spain overcame this by allowing joint citizenship, but nationality has proved an obstacle to shared facilities in the divided town of Valka (Latvia)/Valga (Estonia). ${ }^{11}$

Changes in working time and technology are likely to increase pressure for centralisation of care, with greater use of shared facilities. Experience so far is positive and the practical issues seem resolvable if there is the will to do so.

\section{People sent abroad by their home systems}

Purchasers may establish procedures to allow patients to go abroad for care in two situations. The first is to overcome a shortage of domestic provision, such as Norway's Medical Treatment Abroad Project, which was used to reduce waiting lists for elective surgery. ${ }^{12}$ These schemes typically involve large numbers of patients but are time limited, allowing authorities to develop domestic capacity. The UK government also used this approach to challenge what it saw as unresponsive domestic providers in England. Under short lived projects, a few patients were referred to Belgium, France, and Germany with much publicity. The second situation arises when a small country, such as Malta, makes an explicit decision to obtain highly specialised services abroad because its population is insufficient to justify them. ${ }^{13}$

Most patients referred abroad are positive about their treatment, although postoperative management is a common concern. ${ }^{14}{ }^{15}$ Minor administrative problems may also arise. Success requires support from all stakeholders, especially referring doctors. When the schemes are used as a threat to domestic providers, health professionals may be unwilling to cooperate, with adverse consequences for continuity of care.

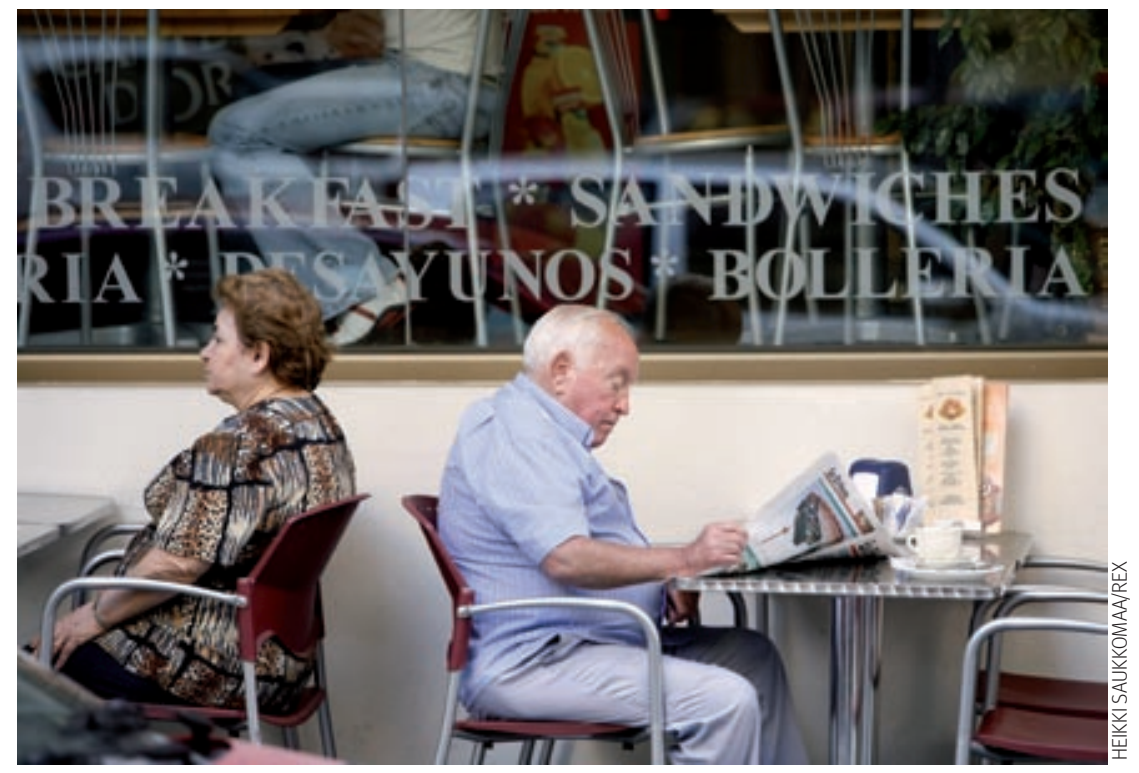

When people from northern Europe retire to southern Europe their healthcare entitlement is transferred to their new country

\section{People going abroad on their own initiative}

Despite their prominence in cases brought before the European Court of Justice, few patients travel abroad specifically to obtain treatment and, in most cases, their treatments lie on the margins of what is funded by their healthcare system. Examples include spas, cosmetic surgery, and dental treatment. ${ }^{16}$ Some of the European Union's new member states view their low costs as an opportunity to attract patients from western Europe. In some cases they have been successful, with dentists in border areas of Hungary and Slovenia attracting patients from other member states, particularly Austria. Elsewhere, however, expected flows have not materialised, partly because of competition from countries with even lower costs, such as India or South Africa.

Some patients also go abroad for more mainstream care because they believe the care is of higher quality. ${ }^{17}$ Some of this movement is well established-for example, from Italy to France- but movement of citizens of the new member states is more recent. The volume is not well documented, and official data on mobility are clearly a substantial underestimate.

The final group is patients who seek interventions that are prohibited at home. Examples include the many women travelling from Ireland to the United Kingdom to obtain abortions and the smaller number of British women going to Spain for late term abortions. ${ }^{18}$ People seeking treatment for infertility and sperm and egg donors are also increasingly moving across borders to obtain donor anonymity.

\section{Future challenges}

Free movement of people and services within Europe makes it impossible to isolate health care behind national barriers. Although the numbers so far are few, the potential exists for large numbers of people to assert their right to obtain care abroad. The crucial issue is who pays and how much. When prior 
authorisation is required, the patient's home health system pays the established price in the system providing treatment. This could result in providers in new member states, such as Poland, facing a very large bill should a patient seek treatment in, say, Germany.

When prior authorisation is not required, the situation is complex. The amount reimbursed depends on factors such as the relative prices in the two countries concerned and levels of copayments. In essence, the determining factor is whether the cost to the patient is seen as a barrier to free movement. However, this creates considerable uncertainty for the patient.

Access to medical information is a common problem. Several countries have implemented electronic patient record systems but, inevitably, these are incompatible with each other. For example, some countries have decided to incorporate electronic patient data into the new European Health Insurance Card but some, such as Spain and Portugal, use magnetic strips and others, such as Austria, France, and Germany, use electronic chips.

Looking ahead, it is important to recognise the potential consequences of European competition law on health services. ${ }^{12}$ Rulings in the education and other sectors suggest that national health services, in which the money allotted to a service is not a direct compensation for the service provided to the patient, lie outside its provisions. However, the creation of a market within national systems, as in England, could open the health sector to competition law. This would allow prospective market entrants, such as multinational corporations, to challenge existing NHS contracts, potentially destabilising even further existing patterns of provision and making coordinated reconfigurations more difficult.

The European Commission has called for legal certainty about patient mobility. In some cases this will be relatively straightforward, simply requiring clarification of how existing legal principles apply to health care, such as those on liability in the event of problems with cross border contracts. In others it will require reaching a political consensus on the role of the market in the provision of health care. Within Europe there is broad agreement that market mechanisms should be managed to ensure that citizens have equitable access to a balanced package of health services.

One way forward is for legal reforms to build on the current regulation, clarifying areas it left unresolved. Each member state would have to develop mechanisms to determine what it considered "undue delay" and have systems in place to ensure minimum standards for safety and quality among its providers. It would also mean that Europe's citizens would have to accept that they would need to obtain prior authorisation if they wanted to go abroad specifically to receive certain types of treatment, but at least the process would be more transparent than at present.

\section{Within Europe there is broad agreement that market mechanisms should be managed to ensure that citizens have equitable access to a balanced package of health services}

\section{SUMMARY POINTS}

Free movement of people within Europe makes cross border care important

Sharing facilities in border areas has many benefits but presents practical problems

The special needs of people retiring to other European countries are not adequately met

A compromise is needed to ensure access to care without damaging the sustainability and integrity of national health systems

Contributors and sources: This article summarises key findings from a major study on patient mobility in Europe ${ }^{5}$ and systematic reviews of projects to support patient mobility in Europe; mechanisms for assuring quality of care in Europe; and legal aspects of cross border care within the EU. In addition, the findings were discussed with other researchers and with policymakers at workshops in Dublin, Tallinn, Venice, and Ghent during 2005-6. HL-Q and MM drafted the article on the basis of discussions with RB and IG. All authors participated in subsequent drafts. $\mathrm{HL}-\mathrm{Q}$ is guarantor.

Competing interests: None declared.

1 European Commission. Communication from the commission consultation regarding community action on health services. Brussels: European Commission, 2006.

2 European Parliament and Council of the European Union. Council Regulation (EEC) No 1408/71 of 14 June 1971 on the application of social security schemes to employed persons and their families moving within the community. Official Journal L 149 of 05.07.1971.

3 European Court of Justice, Case C158/96 [Raymond Kohll $v$ Union des Caisses de Maladie]. 28 April 1998.

4 Bertinato L, Busse R, Fahy N, Legido-Quigley H, McKee M, Palm W, et al. Cross border health care in Europe. Copenhagen: European Observatory on Health Systems and Policies, 2004.

5 Rosenmoller M, Lluch M. Meeting the needs of long term residents. In: Rosenmoller M, McKee M, Baeten R, eds. Patient mobility in the European Union-learning from experience. Copenhagen: European Observatory on Health Systems and Policies, 2006:59-78.

6 Agasi S. Cross border healthcare in Europe - a perspective from German patients. Eurohealth 2002;8(1):37-40

7 Age Concern Espana. Services. www.acespana.org.

8 Harant P. Hospital cooperation across French borders. In: Rosenmoller M, McKee M, Baeten R, eds. Patient mobility in the European Unionlearning from experience. Copenhagen: European Observatory on Health Systems and Policies, 2006:157-77.

9 Glinos IA, Boffin N, Baeten R. Cross-border care in Belgian hospitals: an analysis of Belgian, Dutch and English stakeholder perspectives. Brussels: Observatoire Social Europeen, 2005.

10 Post B, Stal P. Cross-border urgent medical assistance-Belgium, Germany, the Netherlands. Nijmegen: University of Nijmegen Foundation, 2000.

11 Jesse M, Kruuda R. Cross-border care in the north: Estonia, Finland and Latvia. In: Rosenmoller M, McKee M, Baeten R, eds. Patient mobility in the European Union-learning from experience. Copenhagen: European Observatory on Health Systems and Policies, 2006:23-37.

12 McKee M, Mossialos E, Baeten R. The impact of EU law on health care systems. Brussels: Peter Lang, 2002.

13 Azzopardi Muscat N, Grech K, Cachia J, Xuereb D. Sharing capacities — Malta and the United Kingdom. In: Rosenmoller M, McKee M, Baeten R, eds. Patient mobility in the European Unionlearning from experience. Copenhagen: European Observatory on Health Systems and Policies, 2006:119-36.

14 Lowson K, West P, Chaplin S, O'Reilly J. Evaluation of treating patients overseas- final report. York: York Health Economics Consortium, 2002.

15 Boffin N, Baeten R. Dutch patients evaluate contracted care in Belgian hospitals: results of a patient survey. Brussels: Observatoire Social Europeen, 2005.

16 Albreht T, Pribakovi R, Brinovec JS. Cross-border care in the south: Slovenia, Austria and Italy. In: Rosenmoller M, McKee M, Baeten $\mathrm{R}$, eds. Patient mobility in the European Union-learning from experience. Copenhagen: European Observatory on Health Systems and Policies, 2006:9-21.

17 France G. Cross-border flows of Italian patients within the European Union. Eur J Public Health 1997;7(suppl):18-25.

18 EU Business. Spain to investigate allegations of late-term abortions. www.eubusiness.com/Health/061030185843.mut9wt9

Accepted: 22 December 2006 